\title{
Role of Fine needle aspiration cytology (FNAC) in patients presenting with cervically mphadenopathy referred to Gujarat Adani Institute of Medical Science, Bhuj, Kutch
}

\author{
Upadhyay $\mathbf{J}^{1}$, Shingala $\mathrm{A}^{2}$ \\ ${ }^{1}$ Dr. Jigna Upadhyay, Associate Professor, Department of Pathology, Gujarat Adani Institute of Medical Science, Bhuj, \\ Kutch, Gujarat, India, ${ }^{2}$ Dr. Abhikumar Shingala, MPH candidate, Class of 2018, Tennessee State University, USA.
}

Corresponding Author: Dr. Jigna Upadhyay, Department of Pathology, Gujarat Adani Institute of Medical Science, Bhuj, Kutch, Gujarat. Email: researchguide86@gmail.com

\begin{abstract}
Background and Aim: Fine Needle Aspiration Cytology (FNAC) is a simple, quick and inexpensive method that is used to sample superficialmasses like cervical lymph node found in the neck and is usually performed in the outpatient clinic. Cervically mphadenopathy is a common clinical presentation across patients of all age group. The aetiology may range from a benign nonspecificin flammation to lymphoproliferative disorders and metastatic malignancy. The present study was undertaken to study non neoplastic and neoplastic lesions of enlarged lymph nodes by Fine needle aspiration cytology (FNAC) in patients presenting with cervical lymphadenopathy referred to pathology department from the Gujarat Adani Institute of medical science, Bhuj, Kutch over a period of two years. Methods: Total of 850 patients were subjected to FNAC of cervical lymph nodes over two years period. Since in 35 patients, the aspirate was inadequate the remaining 815 cases were analyzed. Results: Overall tuberculous lymphadenitis was the most common finding (42.45\%), followed by reactive hyperplasia (35.09\%). Malignant pathology accounted for $20.24 \%$ of cervical lymph node enlargement, most of which was due to metastaticsquamous cell carcinoma (65.4\%). Conclusion: This study highlights the usefulness of FNAC as a reliable method for diagnosis of cervical lymphadenopathy
\end{abstract}

Key words: Fine Needle Aspiration Cytology, Lymphadenopathy, Neoplastic, Squamous cell carcinoma

\section{Introduction}

Lymphadenopathy is an abnormal increase in size and altered consistency of lymph nodes. It is a clinical manifestation of regional orsystemic disease and serves as an excellent clue to the underlying disease. Cervical lymphadenopathy is a common clinical presentation across patients of all age group. The aetiology may range from a benign nonspecific inflammation to lymphoproliferative disorders and metastatic malignancy. FNAC is widely used as first line investigation for the diagnosis of lymphadenopathy. This simple, easy and quick technique can diagnose reactive, infective and malignant conditions. Several studies in the past have documented the diagnostic accuracy of FNAC with reference to cervical lymphadenopathy among patients presenting to tertiary care institution to evaluate the diagnostic efficacy of FNAC [1-4].

Manuscript received: $28^{\text {th }}$ December 2017

Reviewed: $6^{\text {th }}$ January 2018

Author Corrected: $14^{\text {th }}$ January 2018

Accepted for Publication: $18^{\text {th }}$ January 2018
Fine needle aspiration (FNA) cytology enables a simple and rapid diagnostic approach of patients with lymph node enlargement. Several studies in the past have documented the diagnostic efficacy of FNAC in lymphadenopathy The present study was undertaken to study non-neoplastic andneoplastic lesions of enlarged lymph nodes by Fine needle aspiration cytology (FNAC) in patients presenting with cervically mphadenopathy referred to cytopathology department from the OPD/IPD of Department of Pathology, Gujarat Adani Institute of Medical Science, Bhuj, Kutch, Gujarat over a period of two years.

\section{Materials and Methods}

Study Design, Study Population and Study Duration- This study was carried out over a period of two years at a tertiary care institute Department of Pathology, Gujarat Adani Institute of Medical Science, Bhuj, Kutch, Gujarat, India. 


\section{Original Research Article}

Sampling Methods and Sample collection- A total of 850 patients with cervical lymphadenopathy was subjected to FNA Cusing $23 \mathrm{G}$ needle and a $10 \mathrm{ml}$ disposable syringe. The slides were bothair dried and wet fixed in alcohol for May-Grunwald Giemsa and Papanicolaou stain respectively.

Clinical records and details of information like of age, sex, site, size, duration, involvement of other lymph nodes and other investigations were done.

The cases were divided into following groups, viz.: (a) Reactive hyperplasia: Smears were very cellular, showing a polymorphous population of lymphoid cells and histiocytes. (b) Tuberculously mphadenitis: showed epithelioid cell granulomas with or without caseous necrosis and giant cells. Smears showing only caseousnecrotic material and lymphocytes were also grouped as tuberculous inflammation. (c) Metastatic malignancy: revealed malignant cells inclusters or scattered discretely along with other lymphoid cells.
Metastatic carcinoma was subdivided (e.g. Squamous cell carcinoma, adenocarcinoma, etc.) according to cytological features (d) Lymphoma: cases with a mixed cell population and the characteristic Reed-Sternberg giant cell were categorized as Hodgkin's lymphoma. Non - Hodgkin's lymphoma showed a monomorphous population of small lymphoid cells or lymphoblast. (e) Miscellaneous group: showed features which conform to none of the above mentionedgroups (e.g. Rosai Dorfmann disease).

Statistical Analysis- Qualitative data will be expressed as percentages and proportions. Quantitative data will be expressed as mean and standard deviation. The differences between two groups with respect to continuous variables will be analysed using t-test while categorical variables will be analysed using chi-square test. All the statistical tests will be performed in SPSS version 15 software. $\mathrm{P}$ value $<0.05$ will be considered as statistically significant while $\mathrm{P}$ value $<0.01$ will be considered as statistically highly significant.

\section{Results}

In this study 850 patients were subjected to FNAC for cervically mphadenopathy. Among these patients, in 35 cases, the aspirate was inadequate despite repeated procedure. Hence these 35 cases wereexcluded from study and we proceeded to analyse the remaining 815 cases. The male: female ratio in this study was $1.36: 1$, the mean age of presentation being 30.9 years and 26.8 years for male and female patients respectively. The age at presentation ranged from 6 months to 70 years. We received the maximum number of patients $(23.68 \%)$ inthe $21-30$ years age group, and the least $(2.94 \%)$ in the $>60$ years age category (Table 1).

Table-1: Age wise distribution of cases.

\begin{tabular}{|c|c|c|c|c|c|c|c|}
\hline $\begin{array}{c}\text { Age } \\
\text { groups }\end{array}$ & $\begin{array}{c}\text { Reactive } \\
\text { Hyperplasia }\end{array}$ & TB & NHL & $\begin{array}{c}\text { Hodkins } \\
\text { lymphoma }\end{array}$ & Metastasis & Others & Total \\
\hline$<\mathbf{1 0}$ & 58 & 11 & 1 & 0 & 0 & 4 & 74 \\
\hline $\mathbf{1 1 - 2 0}$ & 101 & 35 & 0 & 2 & 1 & 2 & 141 \\
\hline $\mathbf{2 1 - 3 0}$ & 43 & 137 & 1 & 0 & 8 & 4 & 193 \\
\hline $\mathbf{3 1 - 4 0}$ & 29 & 70 & 2 & 1 & 11 & 7 & 120 \\
\hline $\mathbf{4 1 - 5 0}$ & 27 & 52 & 5 & 4 & 39 & 1 & 128 \\
\hline $\mathbf{5 1 - 6 0}$ & 22 & 34 & 9 & 1 & 60 & 1 & 127 \\
\hline$>\mathbf{6 0}$ & 6 & 7 & 2 & 0 & 17 & 0 & 32 \\
\hline Total & $\mathbf{2 8 6}$ & $\mathbf{3 4 6}$ & $\mathbf{2 0}$ & $\mathbf{8}$ & $\mathbf{1 3 6}$ & $\mathbf{1 9}$ & $\mathbf{8 1 5}$ \\
\hline
\end{tabular}

Tubercular lymphadenitis $(42.45 \%)$ was overall the most common cause of lymphadenopathy. Most of, the cases occurred between 21-30 years.

Reactive lymphoid hyperplasia was the second most common finding (35.09\%) predominantly in the age group 0f $11-20$ years. As expected, the percentage of malignant cases rose steadily with age and accounted for $42.30 \%$ cases of cervical lymphadenopathy in patients more than

50 years of age. Malignant pathology accounted $20.24 \%$ cases of cervically mphadenopathy (Table 1). Of these neoplastic lesion, metastaticly mphadenopathy $(82.42 \%)$ was most common. Rests of the neoplastic cases were NHL $12.72 \%$ and Hodgkins lymphoma $4.84 \%$. 


\section{Original Research Article}

Among the metastatic lesion, squamous cell carcinoma topped thechart with $65.4 \%$, as opposed to metastatic adenocarcinoma $29.41 \%$ found in only cases. Other than these, there were 2 cases of meta staticnasopharyngeal carcinoma (1.47\%), 4 undifferentiated carcinoma $2.94 \%$ and a single case of metastatic malignant melanoma. Besides the above mentioned causes of lymph node affliction, wenoted three cases of Cat scratch disease, six cases of Rosai Dorfman disease (sinus histiocytosis with massive lymphadenopathy). All 6 patients were less than 15 years of age. Malignant lesions were more inthe $>50$ years age group whereas in all other age groups tuberculous lesions predominated.

\section{Discussion}

Cytology of cervical lymph node is the first investigation in diagnosis of many diseases in tertiary care settings [5]. FNAC of cervical lymphnodes helps to explore the various lesions that involve these In the present study males were more commonly involved than females with male:female ratio of 1.36:1. Age of patients showed a wide range starting from as early as 6 months to 70 years old, most of the cases occurring between 20-29 years of age group. Similar findings were observed by Pandav AB et al. [5] and Shakera N Baji and co-workers [6]. Since infections from oral cavity, ears, nose, and para nasal sinusesdrain into cervical nodes, reactive lymphoid hyperplasia is a common finding [7]. However, in our study tuberculous lymphadenitisemerged as commonest $(42 \%)$ cause of cervical lymphadenopathy.

Lymphadenopathy presents an opportunity for a quick and efficient way to reach an early diagnosis through fine needle aspiration cytology (FNAC) of the involved lymph node. Lymph nodes react to a variety of microorganism and non specific stimuli by expansion of follicle centers and / or intrafollicular tissue. Since infections from oral cavity, ears, nose and paranasal sinuses drain into the nodes, reactive lymphoid hyperplasia is a common finding. Germinal centres may be very large in some cases of reactive follicular hyperplasia. If the aspirate derives from such a large germinal centre, the proportion of large cells (centroblasts, dendritic reticulum cells) and the number of mitoses may be impressive enough to suggest malignant lymphoma. However, the full range of lymphocyte transformation is still present, including small lymphocytes and the various cell types occur in logical proportions. Small lymphocytes are numerically predominant. A variable number of plasma cells can usually be found. The presence of macrophages with tingible bodies favors reactive hyperplasia.

Most of the cases occurred between 20-29 years of age. A declining trend in cases has been observed after 30 years of age. This corroborates with other studies conducted by other studies [8]. The high incidence of tuberculosis may be explained by the fact of low socioeconomic condition, poorhygiene and lack of awareness in the region. Reactive lymphoid hyperplasia was the second most common lesion, commonly in the younger age group. Males were affected morethan females. These findings correlate with study by Shakera $\mathrm{N}$ Baji and coworker [8]. The incidence of reactive lymph node enlargement fell steadily the 5th decade onwards and malignant lesions being most common. Among the malignant lesion, metastatic lymphadenopathy $(80 \%)$ wasthe most common and predominant cause in patients ranging from 40 years and above. Rest of the cases were that of NHL (12.8\%) and Hodkins lymphoma (4.9-\%). These findings are similar to studies by K. Bhuyan Medhi et al[9]. Among the metasticlesions, squamous cellcarcinoma $(65 \%)$ was the commonest. Metastatic squamous cellcarcinoma was found to be more common in males and most of the cases occurred between 50-59 years of age. Similar observation wasnoted in studies done by Nath $\mathrm{s}$ et al[10] Metastatic adenocarcinoma and few cases of undifferentiated carcinoma constituted the rest of malignant lesions. The high incidence of metastatic lymphadenopathy may be due to high incidence of malignancy of Head and neck region inthis geoeconomic block. We noted 8 cases of Rosai Dorfman syndrome. It is a benign condition and some rare causes of cervical lymphadenopathy [11]. It usually occurs inthe first decade of life and manifest as massive enlargement of cervicallymph nodes.

\section{Conclusion}

The most frequent causes ofcervical lymphadenopathy are tuberculosis, reactive lymphadenitis, and metastatic malignancies. In large number of cases FNAC alone isenough for diagnosis in proper clinical setting and surgical procedures like biopsy can be avoided even in tertiary care settings.

What this study addto existing knowledge? This study highlights the usefulness of FNAC as a reliable method fordiagnosis of cervical lymphadenopathy. Exactearly diagnosis can save the patient from high mortality and morbidity especially in malignant diseases. 


\section{Original Research Article}

Funding: Nil, Conflict of interest: None initiated Permission from IRB: Yes

\section{References}

1. Steel BL, Schwartz MR, Ramzy I. Fine needle aspiration biopsy in the diagnosis of lymphadenopathy in 1,103 patients. Role, limitations and analysis of diagnostic pitfalls. Acta Cytol. 1995 Jan-Feb; 39 (1): 76-81.

2. Nasuti JF, Yu G, Boudousquire A, Gupta P. Diagnostic value of lymph node fine needleaspiration cytology: an institutional experience of 387 cases observed over a 5 yearperiod. Cytopathology 2000;11 (3):18-31.

3. Gupta RK, Naran S, Lallu S, Fauck R. The diagnosticvalue of fineneedle aspiration cytology (FNAC) in the assessment of palpable supraclavicularlymph nodes: a study of 218 cases. Cytopathology. 2003 Aug;14(4):201-7.

4. Bhaskaran CS, Kumar GH, Sreenivas M, Kameswari R, Rao G, Aruna CA. Fine needle aspiration cytology. Review of 1731 cases. Indian J Pathol Microbio 11990; 33 (4):387-97.
5. Pandav $\mathrm{AB}$ et al.Cervical LymphadenopathyDiagnosis by FNAC: A study of 219cases.Asian Journal of Medicine, Ref:2012,1(3);79-83.

6. BajiS.N.Analysis of FNAC of cervical lymph nodes. Experience over a two-yearperiod. International Journal of medical sciences andpublic health.2014;3(5):607-609

7. BargotaR. A cytological study of cervical lymphnodes in a tertiary care center. J K science 2015; 17(7):13-15

8. Khadka S., Shrestha D. Evaluation of fine needle aspiration of cervically mphadenopathy in Bir hospital. Jcms. 2015;11(1):22-25.

9. Medhi K Pattern of various lymph node lesions in Fine needle aspiration cytologyin patients presenting with lymphadenopathy. A in a tertiary care hospital of North East India, IJPR2016;6(5):334-337.

10. Nath S. et al. Cyto diagnosis of metastatic cervical lymphadenopathy in a tertiary carecentre in North EastA one year study. NJMR 2015;5(4):296-299.

11. Russell J, Orell S, Skinner J, Seshadri R. Fine needle aspiration cytology in the management of lymphoma. Aust N Z J Med. 1983;13(3):365-368.

\section{How to cite this article?}

Upadhyay J, Shingala A. Role of Fine needle aspiration cytology (FNAC) in patients presenting with cervically mphadenopathy referred to Gujarat Adani Institute of Medical Science, Bhuj, Kutch. Trop J Path Micro 2018;4(1):113116. doi: 10.17511/jopm.2018.i1.20 